\title{
Construcción del patrimonio: la movilización de la memoria colectiva en localidades mineras de Coahuila, México
}

Heritage Construction: the Mobilization of the Collective Memory in Mining towns in Coahuila, Mexico

\author{
Camilo Contreras Delgado \\ Departamento de Estudios Culturales (DEC), \\ El Colegio de la Frontera Norte (Colef), México \\ camilo@colef.mx
}

\section{Resumen}

Este INFORME sostiene la idea de que el patrimonio cultural es un proceso en constante creación, para lo cual se documentan dos instancias que resultan del trabajo de campo del proyecto denominado "Patrimonio industrial minero. Exploración y posibilidades de valoración en la cuenca carbonífera de Coahuila", hoy en curso. Los dos casos son el baile de "El viandero", de Nueva Rosita (municipio de San Juan de Sabinas), y la actividad del grupo civil "Coterráneos de Rancherías" (municipio de Múzquiz). Esta contribución busca cumplir los dos propósitos del proyecto general en la que está inscrito: por un lado, identificar las expresiones intangibles asociadas a la minería del carbón, tales como las representaciones artísticas, los rituales, los conocimientos y técnicas, así como los movimientos sociales emblemáticos y, por otro lado, conocer los significados que reviste el patrimonio tangible e intangible para los pobladores de la cuenca carbonífera de Coahuila en un contexto de desindustrialización. Entrevistas no estructuradas a miembros de estas localidades muestran que, incluso en ese contexto, la memoria colectiva asociada con el trabajo minero resurge de diferentes formas para objetivarse como patrimonio. La información recabada indica, asimismo, que el patrimonio no sólo es una selección e interpretación del pasado, sino también una construcción desde el presente, proyectada hacia el futuro por medio de los valores que se quieren conservar $y$ transmitir.

\section{Palabras clave}

memoria; identidad; patrimonio minero; patrimonio industrial; paisaje cultural; Coahuila; México

\section{Abstract}

This REPORT supports the idea that cultural heritage is a process in constant creation. For this, it documents two case studies resulting from the field work of the current project called "Mining industrial heritage. Exploration and assessment possibilities in the coalfield of Coahuila": the "EI viandero" dance, from Nueva Rosita (municipality of San Juan de Sabinas), and the activity of the civil group "Coterráneos de Rancherías" (municipality of Múzquiz). The purposes of this contribution concur with those of the above-mentioned general project: on the one hand, to iden- 
tify the intangible expressions associated with coal mining, such as artistic representations, rituals, knowledge and techniques, as well as emblematic social movements and, on the other hand, to comprehend the meanings that surround the tangible and intangible heritage for the inhabitants of the coalfield of Coahuila in a context of deindustrialization. Non-structured interviews of members of these towns show that, even in such context, the collective memory associated with the mining work reemerges in different manners to take shape as heritage. Likewise, the information collected indicates that heritage is not only a selection and interpretation of the past but also a construction of the present, projected towards the future through the values that we want to preserve and convey.

\section{Key words}

memory; identity; mining heritage; industrial heritage; cultural landscape; Coahuila; Mexico

\section{Introducción}

El patrimonio cultural, como construcción social, es un proceso activo e identificable en las prácticas culturales cotidianas. Algunos autores mencionan que la selección implícita en esta construcción es un ensamble del pasado desde el presente que alude a la agencia colectiva (Harrison 2013:32). Para evidenciar lo anterior, el presente INFORME se apoya en los hallazgos preliminares del trabajo de campo del proyecto "Patrimonio industrial minero. Exploración y posibilidades de valoración en la cuenca carbonífera de Coahuila", iniciado en el 2015. Aquí se tratan únicamente dos de las localidades del proyecto general: Rancherías (municipio de Múzquiz) y Nueva Rosita (municipio de San Juan de Sabinas). Con la información obtenida en entrevistas no estructuradas a miembros de estas comunidades se muestra que, incluso en un contexto de desindustrialización, la memoria colectiva asociada con el trabajo minero resurge de diferentes formas para objetivarse como patrimonio. El desarrollo del artículo presenta el contexto de la región estudiada, una nota metodológica y conceptual, un comentario sobre la identidad regional y local, la exposición de los casos de la construcción social del patrimonio y, por último, algunas reflexiones a manera de conclusión.

\section{Antecedentes}

En más de 120 años de actividad minera, la cuenca carbonífera, ubicada en el centro norte de Coahuila, México, ha visto pasar diferentes etapas económicas, sociales y tecnológicas. La dinámica regional detonó hacia la década de 1890 con el tendido de rieles para conducir el mineral fuera del país y, posteriormente, a sitios con fuerte presencia industrial, como Monterrey. A la par de unidades e infraestructura productivas (minas, hornos de coquización, lavadoras de carbón, generadoras de electricidad, locomotoras y vías de ferrocarril) aparecieron gradualmente espacios para la reproducción social (viviendas de mineros y sus familias, escuelas, locales sindicales, cooperativas de consumo, hospitales e iglesias) que cambiaron el paisaje del semidesierto de esa región del estado (Sariego 1988a:58-66).

Entre las localidades surgidas por la actividad minera del carbón están: San Felipe y El Hondo, Nueva Rosita, Las Esperanzas, Cloete, Agujita, Minas de Barroterán, San José de Aura, La Luz y Rancherías, todas ellas repartidas en cinco municipios: Múzquiz, San Juan de Sabinas, Sabinas, Juárez y Progreso (Sariego 1988a:58-66) (Figura 1).

Algunas de estas localidades han desaparecido con la lógica del agotamiento del carbón o de la imposibilidad de explotarlo; las demás se han mantenido hasta nuestros días gracias a la estructuración de un mercado de trabajo regional alrededor del carbón (con desplazamientos pendulares de los trabajadores), a la aparición de otras fuentes de trabajo (la maquila) y a las transferencias monetarias enviadas por gente que ha emigrado (Contreras 2002). Varios especialistas han estudiado estos aspectos desde la antropología, la sociología, la geografía y la historia (cfr. Novelo 1980; Reygadas 1988; Sariego 1988a; Cerutti 1995). También destacan las publicaciones, principalmente, las de corte históri$\mathrm{CO}$, de autores de las localidades mineras (cfr. Flores 1993).

A más de un siglo de explotación minera, esta región continúa como la única proveedora de carbón mineral del país (Secretaría de Economía 2011). Durante este largo trayecto, la cuenca ha funcionado ya en contextos de expansión en inversión privada nacional y extranjera, ya en el periodo de sustitución de importaciones o en la etapa privatizadora, con la reestructuración económica y apertura de fronteras en las décadas de los ochenta y noventa del siglo pasado, o bien, actualmente, en la época de desindustrialización (Sariego 1988b). Además de la infraestructura para la producción y para la reproducción mencionadas, en la cuenca carbonífera de Coahuila se formó una cultura propia de los sitios mineros, cuyas representaciones sociales se dieron alrededor de la actividad sindical, el trabajo de extracción propiamente dicho, los accidentes y las relaciones de género, así como en algunas expresiones artísticas (Canales 1989). Hoy algunos de los hechos sociales más emblemáticos se siguen conmemorando en las localidades aunque la actividad minera acusa en algunas declive o, en otras, concentración: parte de esto es lo que se trata en esta contribución.

Si bien con este brevísimo contexto pareciera que las manifestaciones comunitarias y culturales asociadas a la minería del carbón estarían en franco debilitamiento, nos hemos encontrado con lo que Bradley (1996:25) denomina identidades potenciales o dormidas. Esto es, pese a que en el actual contexto socioeconómico, con nuevas generaciones y relaciones de género, la minería del carbón y los sistemas de significados vinculados con ella parecen desarticularse, la innovación cultural desde nuevos sujetos despierta ese sentido 


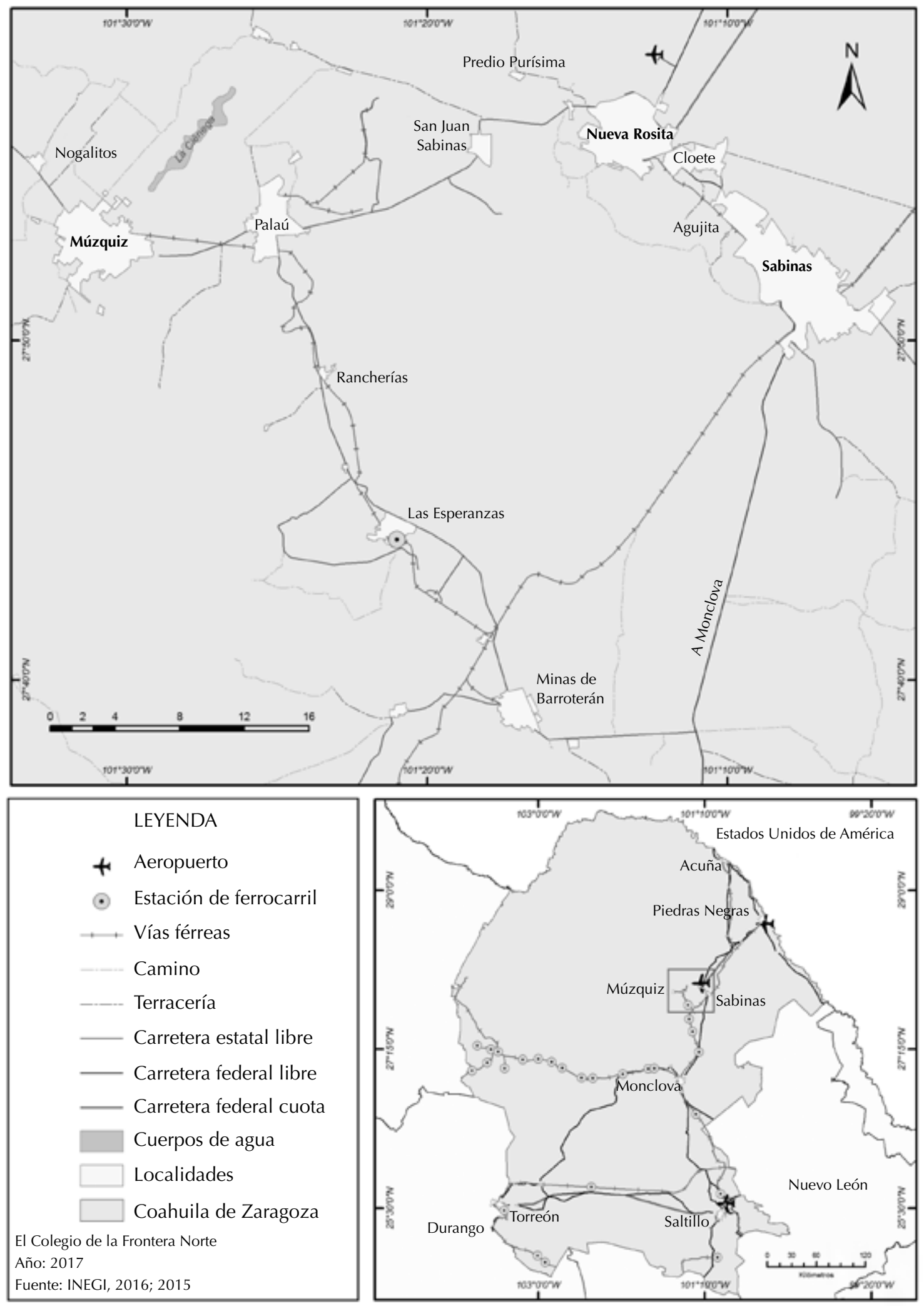

FIGURA 1. Ubicación de la cuenca carbonífera de Coahuila (Mapa: Gustavo Adolfo Vázquez, 2017). 
de pertenencia a culturas ancladas en tiempos y territorios más o menos definidos, con lo que el patrimonio - el patrimonio como proceso- se pone en movimiento.

\section{Nota metodológica}

Como hemos mencionado, este INFORME es un primer acercamiento al trabajo de campo del proyecto más vasto, que se propone registrar parte del patrimonio tangible e intangible de la cuenca carbonífera de Coahuila, en el que asumimos que el patrimonio industrial está constituido por aspectos tanto productivos (infraestructura para la producción) como reproductivos (viviendas, escuelas, templos, lugares de ocio para los trabajadores y sus familias). De la misma manera, el patrimonio industrial incluye aspectos inmateriales, como los saberes técnicos, la organización del trabajo y las representaciones artísticas en que la actividad industrial se pone en escena. Uno de los principios que guían el proyecto es que hablar de patrimonio no sólo es hablar del pasado. Retomamos la crítica de Sommer (2009:103) de que cuando se toca el tema del patrimonio uno de los verbos más usados es "preservar", cuando en realidad es más acertado hablar de "crear", puesto que para interpretar el presente y dibujar expectativas para el futuro no se toma sino solamente una parte del pasado. Así, apenas una selección de acontecimientos pasados se usa para la creación y el reforzamiento de las identidades colectivas.

La entrevista no estructurada ${ }^{1}$ nos ha permitido vincular dos aspectos: el pasado con el presente y lo tangi-

\footnotetext{
1 La entrevista no estructurada es particularmente útil cuando se aspira a entender y captar los significados de un grupo determinado. De acuerdo con Schwartz y Jacobs (1984:65), las preguntas surgen en el proceso de interacción que ocurre entre el entrevistador y los entrevistados. De esta forma es posible identificar temas con sentido para el entrevistado, mientras que el entrevistador gana en sensibilidad.
}

ble con lo intangible. Todo esto, por supuesto, desde la perspectiva de los sujetos. Creemos que la entrevista no estructurada es una herramienta adecuada cuando se requiere entender el patrimonio como una creación, como una interpretación desde los sujetos y desde su presente, cuando queremos entrar en el mundo de los significados del paisaje, de los muebles e inmuebles. La entrevista en la investigación del patrimonio es uno de los antídotos para evitar la fragmentación de lo tangible e intangible. Autores como Sorensen (2009:164) enfatizan que para quienes estudian el patrimonio la entrevista es un medio para obtener información sobre las relaciones abstractas y complejas, así como acerca de los sentimientos de la gente por el pasado.

La información para esta contribución se recabó en dos localidades coahuilenses: Nueva Rosita (municipio de San Juan de Sabinas) y Rancherías (municipio de Múzquiz). Las personas entrevistadas son extrabajadores mineros, profesoras jubiladas, profesores de danza y cronistas locales. De acuerdo con Garden (2009:271): "Ios sitios patrimoniales ocupan un espacio tanto en el paisaje físico como en el paisaje de la memoria". Por lo tanto, asumimos que los sitios conectan con el pasado y que son relevantes para la reproducción de la identidad, ${ }^{2}$ pero hay un punto más en el que debemos insistir: no son lugares aislados. La vivienda, la escuela, la mina, el local sindical, la cooperativa ni son recordados ni son resignificados como puntos discretos. Esto tiene implicaciones tanto teóricas como metodológicas. En la aplicación de las entrevistas fue necesario considerar lo que la gente recuerda de los cambios que ha vivido junto con sus propias localidades y cómo las ruinas $u$ otros inmue bles adquieren sentido en el tiempo y en la transformación del entorno.

\footnotetext{
2 En este sentido, Giménez (2007:217) comenta que el patrimonio está estrechamente ligado a la memoria colectiva y, por ende, a la construcción de la identidad de un grupo o de una sociedad.
}

Apunte conceptual

Al retomar a algunos autores sintetizamos la idea de que el patrimonio es una construcción social. Por ejemplo, Harrison (2013:32-35) plantea que: a) el patrimonio no es un mecanismo pasivo de conservación de cosas del pasado, sino un proceso activo en el que se ensambla una selección de objetos, prácticas y lugares para contrastar con el presente, asociado, además, a una serie de valores que se desea conservar para el futuro, y $b$ ) al explorar el patrimonio como una producción del pasado en el presente surgen las preguntas de quién está detrás de esa producción, lo que invoca directamente la cuestión de la agencia y el poder. Esto permite realizar un análisis más realista sobre la forma en que el patrimonio se produce y usa, ya sea desde la esfera oficial o desde los grupos de la sociedad civil. Muy similar a esta posición, en la reflexión de Soriano y Terrazas (2016:43) el patrimonio puede adquirir una forma de propiedad, o herencia apropiada, desde diferentes grupos, entre los que se encuentran no sólo los de élite, sino también indígenas, obreros, campesinos, entre otros. Por su parte, Timón (2012:23) plantea la autonomía del patrimonio intangible respecto de sus orígenes. Las expresiones patrimoniales inspiradas en el pasado hoy se han convertido en acontecimientos sociales capaces en sí mismos de congregar a una colectividad en el presente. En la misma línea, Byrne (2008:155) también aporta la visión de conjunto: "La gente encuentra huellas de sí misma en los paisajes donde vive o vivió en el pasado. Pero esas huellas no son necesariamente físicas, sino, principalmente, asociaciones, emociones que pueden desencadenarse con ver algún elemento del paisaje, pero también a través de oler o escuchar algo".

Estos apuntes nos facilitarán el análisis y la interpretación de las entrevistas y de los procesos encontrados en campo. Partimos, pues, de que el patrimonio cultural es una construcción social en que los agentes (gubernamentales o grupos de pobladores) 
echan mano de elementos del pasado a los que les confieren sentido desde el presente y con miras a proyectar a futuro ciertos valores.

\section{La conformación de una memoria colectiva regional y local}

Antes de centrarnos en las expresiones que calificamos como patrimoniales, conviene aclarar que, si bien podemos hablar de memoria e identidad en cada localidad, también es necesario tener claro que al mismo tiempo hay una memoria e identidad regional ${ }^{3}$ (tomamos a la cuenca como una región). Esto se explica por las características de la industria minera ${ }^{4}$ y por la concentración de servicios en las localidades principales: en un principio éstas se emplazaron a un lado de las minas; conforme se agotaba el mineral, en algunos casos desaparecieron (por ejemplo, San Felipe, El Hondo, La Escondida), pero en la mayoría de los casos, ya con mejores vías de comunicación, resistieron debido a la formación de un mercado de trabajo regional. Ahora son pueblos dormitorio, en tanto que la mayoría de los trabajadores mineros sale a otras localidades a laborar; lo mismo pasa con las mujeres, quienes laboran en localidades donde se han establecido las maquiladoras (Contreras 2002). Nuestros informantes mencionan algunas otras

\footnotetext{
${ }^{3}$ Para el caso de la cuenca carbonífera de Coahuila se aplica lo que Giménez (2007:137) considera como identidad regional: "se da cuando por lo menos una parte significativa de los habitantes de una región ha logrado incorporar a su propio sistema cultural los símbolos, valores y aspiraciones más profundos de su región".

${ }^{4}$ Los yacimientos mineros son caducos en calidad y cantidad. Gran parte de los pueblos de esta cuenca surgieron por la apertura y explotación de aquéllos. Cuando esta última se vuelve incosteable, se han seguido dos derroteros: el desplazamiento de las familias a otros pueblos de la cuenca (al extremo de que el poblado puede desaparecer) o el desplazamiento pendular de los mineros (vivir en un pueblo y trabajar en otro).
}

motivaciones de la movilidad entre pueblos, además de la laboral: comerciales, de atención médica, educativa, de visita a parientes y amistades, de ocio (como el beisbol, que moviliza muchos aficionados), gente que nació en una localidad y su familia se mudó a otra dentro de la misma región. Todo esto ha configurado una dinámica regional desde el surgimiento de las mismas localidades. Para ejemplificar esta movilidad a lo largo de la vida de sus habitantes, citamos parte de las respuestas a partir de una entrevista a un matrimonio, cuyos miembros nacieron en localidades fuera de Rancherías:

Yo nací en la Villa de las Esperanzas, pueblo vecino, llegué a este pueblo en 1955, me trajeron mis padres porque en aquel entonces estaba la mina de carbón en este pueblo (Anón. 2016a: comunicación personal).

Yo nací en una hacienda del municipio de San Juan de Sabinas, después me llevaron de niño al ejido Rancho Nuevo, también de San Juan de Sabinas, para seguir el segundo año de la escuela me trajeron a Rancherías $-y$, narrando su trayectoria laboral-: tenía 17 años, estuve trabajando en el patio para que cumpliera los 18 para poder bajar a la mina, trabajé 15 años y 7 meses, fue cuando se paró todo porque vendieron todas las minas. Luego trabajé en San Patricio, La Mota, La Luz, luego en el rancho La Víbora (Anón. 2016b: comunicación personal).

Estos no son casos excepcionales. Gran parte de la población experimenta esa movilidad regional por motivos como los ya descritos. Sin embargo, el apego socioterritorial se muestra y se extiende desde la localidad de residencia en círculos concéntricos. Los pobladores definen su localidad como "una casa grande", "un lugar que vimos crecer" (Anón. 2016a: comunicación personal), y ante la pregunta de por qué no se han ido, si ya no hay trabajo, la respuesta es que allí están sus muertos, allí crecieron ellos y sus hijos y allí se conocen todos. Conocen la historia y la geografía local, han sido testigos de los cambios en su paisaje inmediato:

Era muy pequeño el poblado, eran contadas las casas y la mayoría de los trabajadores venía de fuera, pero luego ya la compañía empezó a hacer las casitas y se empezó a ubicar el pueblo. Teníamos cooperativa de consumo, había abarrotes, frutería, carnicería, el sindicato tenía sus oficinas... (Anón. 2016a: comunicación personal).

Al comentar lo que más les atrae del pueblo nos dicen:

El amor que le tenemos al pueblo [es] principalmente [por] la minería, la ganadería, la escuela donde yo participé, allí participó mi esposo, mis hijos y ahora mi nieto (Anón. 2016a: comunicación personal).

El paisaje en su conjunto y algunos de sus elementos dejan de ser solamente objetos, inmuebles materiales, para revestirse de significados. La relevancia de su entorno inmediato es, a la vez, la distinción respecto de otras localidades de la región; de allí que la identidad local esté fuertemente apegada tanto al territorio como a las historias personales, familiares y comunitarias de sus habitantes. Cuando la persona entrevistada habla de "el amor que le tenemos al pueblo" no lo hace en abstracto, sino enumera las principales actividades del lugar (como la minería) y los sitios en los que ella y su familia han tenido experiencias significativas (la escuela). Esto se relaciona con lo que propone Frosh (1999:413): "Para desarrollar sus identidades la gente echa mano de recursos culturalmente disponibles en sus redes sociales inmediatas y en la sociedad como un todo. Por consiguiente, las contradicciones y disposiciones del entorno sociocultural tienen que ejercer un profundo impacto sobre el proceso de construcción de la identidad". 
El cierre de las minas y la búsqueda de nuevas oportunidades de vida han provocado la migración de estos pueblos:

Cuando cerraron la mina y tuvieron que salirse a buscar el sostén para las familias y se llevaron a sus familias fue cuando el pueblo empezó a quedar más solito y más solito y los que nos quedamos no nos queremos salir, aquí nos quedamos (Anón. 2016a: comunicación personal).

Nos encontramos con que una de las categorías de pertenencia son las colectividades territorializadas. Sin embargo, también es importante destacar que las colectividades o

[...] mundos de sentido no son plenamente coherentes, integrados y resistentes al cambio, según el modelo de la etnografía clásica. Más bien debe partirse de la presuposición contraria: frecuentemente están llenos de contradicciones, están débilmente integrados y padecen continua erosión en virtud de los procesos de metropolización, globalización (Giménez 2007:64)

y, añadiríamos nosotros para este caso: migración.

Este fenómeno no es nuevo ni privativo de Rancherías: tiene que ver con la reestructuración de la minería del carbón asociado con la industria siderúrgica. ${ }^{5}$ La negativa a salirse del pueblo está soportada por condiciones reales de retención: además de que se ha conformado un mercado de trabajo regional, al que ya se hizo mención, la gente reconoce la existencia de motivos de arraigo y pertenencia al lugar. Particularmente esta familia no migró porque se quedó a cuidar a sus papás, sigue habitando la vivienda que la compañía minera le otorgó a su padre hace 64 años sin alterarla por mandato de la madre:

\footnotetext{
${ }^{5}$ Minello (1990:208) menciona entre las medidas correctivas para sanear la empresa Altos Hornos de México (AHMSA) el cierre definitivo de empresas filiales que no fueran estrictamente necesarias.
}

Mi mamá, Dios la tenga en paz, nunca quiso que la tumbáramos, tumbamos sólo la mitad. [Mi mamá dijo] que aquí la íbamos a tender [velar] cuando ella se muriera y que no la tumbara y fueron sus deseos y así se cumplió (Anón. 2016a: comunicación personal).

La familia tiene muy clara, como si se tratara de una persona, la edad de la vivienda, sabe cómo se adquirió, así como el aprecio que sus antepasados le tuvieron, según nos dejaron ver en la entrevista. Un sitio material va adquiriendo significados para las diferentes generaciones ( $\mathrm{Fi}$ guras 2, 3a y 3 b). A esta conexión es a la que nos referimos cuando hablamos de no fragmentar lo tangible de lo intangible.

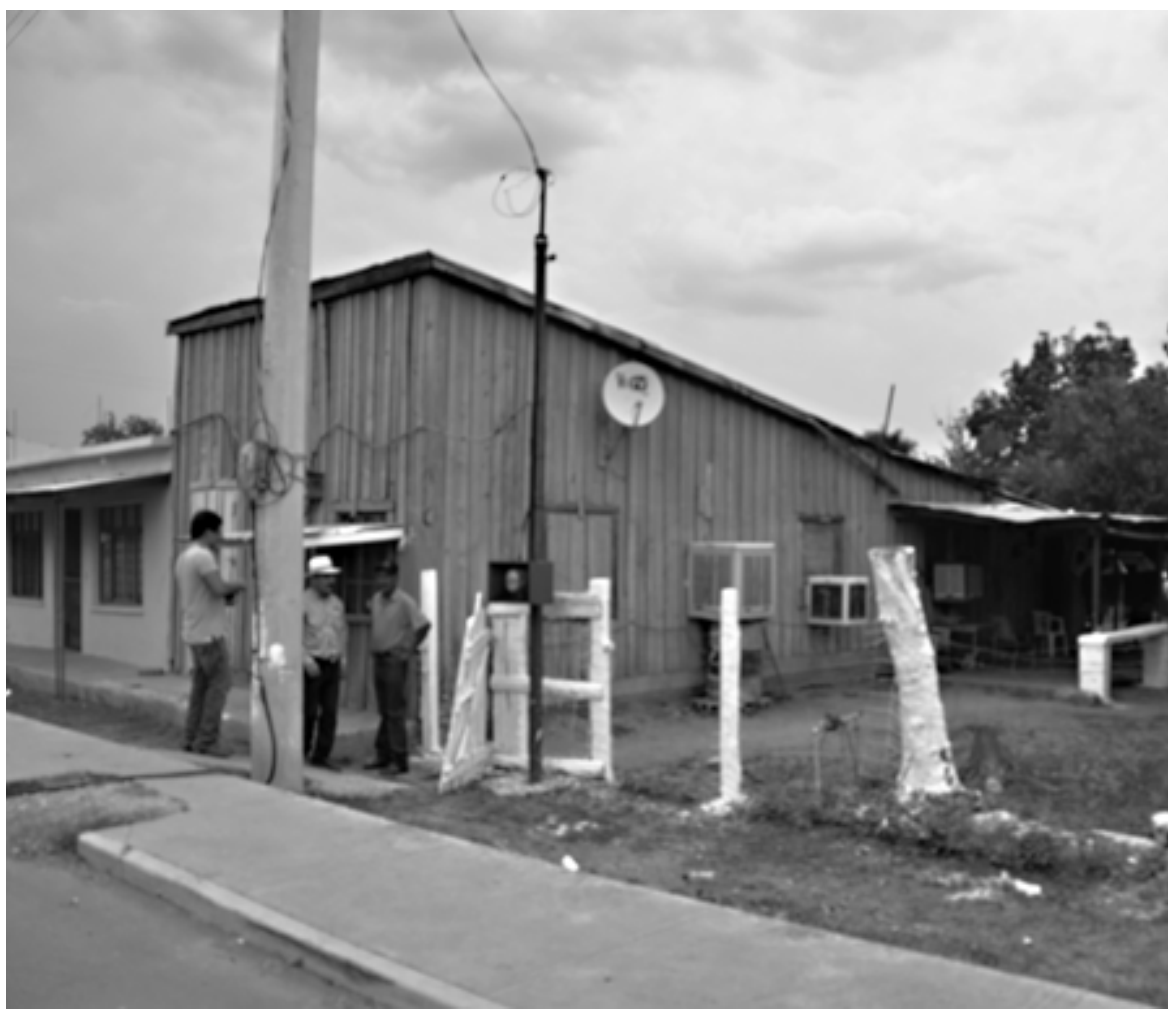

FIGURA 2. Vivienda obrera otorgada por la compañía minera (Fotografía: Alfonso Silva, 2016).

\section{La construcción social del patrimonio desde la sociedad civil}

En este apartado se exploran dos casos de manifestaciones patrimoniales intangibles que sirven para mostrar la manera en que algunas agrupaciones seleccionan, de muy diferentes maneras, rasgos del pasado minero y les dan su propio uso e interpretación en el presente, ya sea para procurar el cambio de condiciones materiales o para transmitir la memoria a las nuevas generaciones. Ambos son iniciativas de grupos ciudadanos, quienes, a pesar de haber recibido apoyo financiero, tienen control sobre sus metas.

Primero nos referimos a la puesta en escena denominada baile de "El viandero". Se trata del reconocimiento al oficio infantil de llevar el alimento al lugar de trabajo de los mineros. El profesor de danza es descendiente de ellos, de acuerdo con nuestros hallazgos, pero, además, indaga la dinámica de los pueblos mineros y sus personajes para represen- 
Casa habitación

Nota: aún se encuentra habitada

Año estimado: 1948

Fachada principal

Fachada trasera
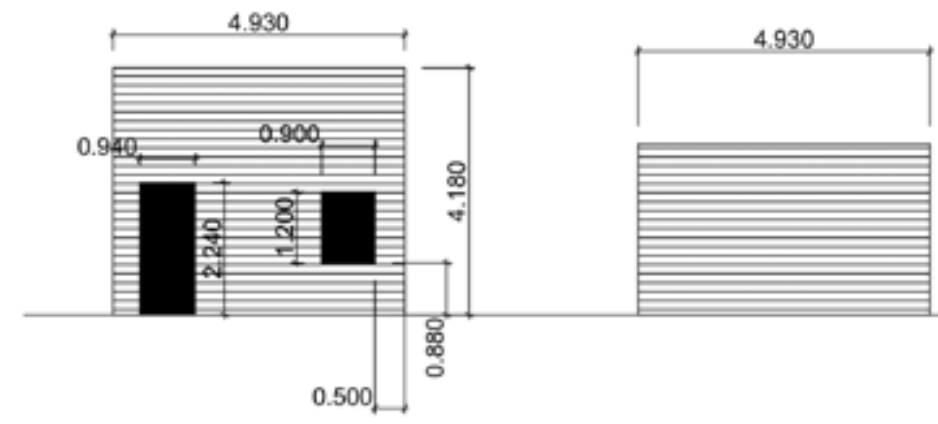

Fachada izquierda

Fachada derecha
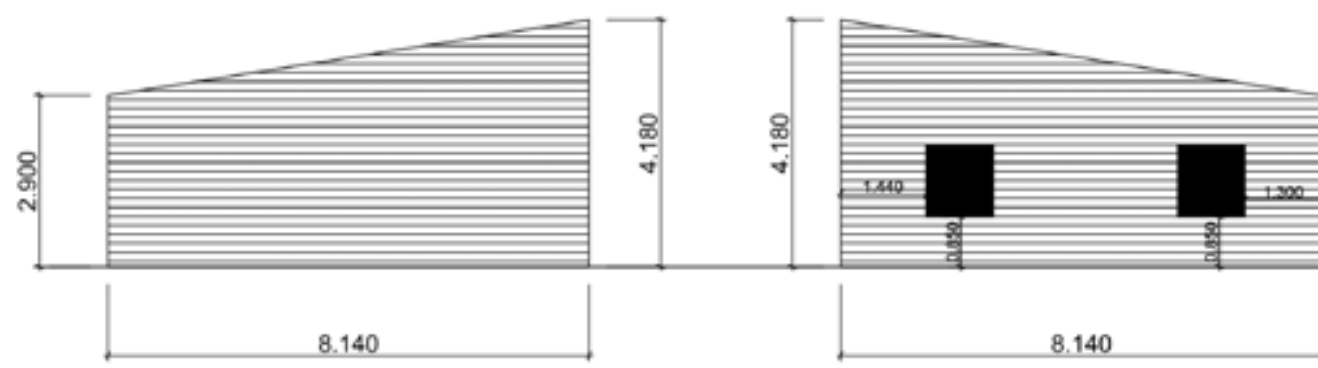

Escala: 1:50

Unidad de medida: metros 
Solar: es el terreno el cual se le otorga a una cantidad de trabajadores para que habiten.

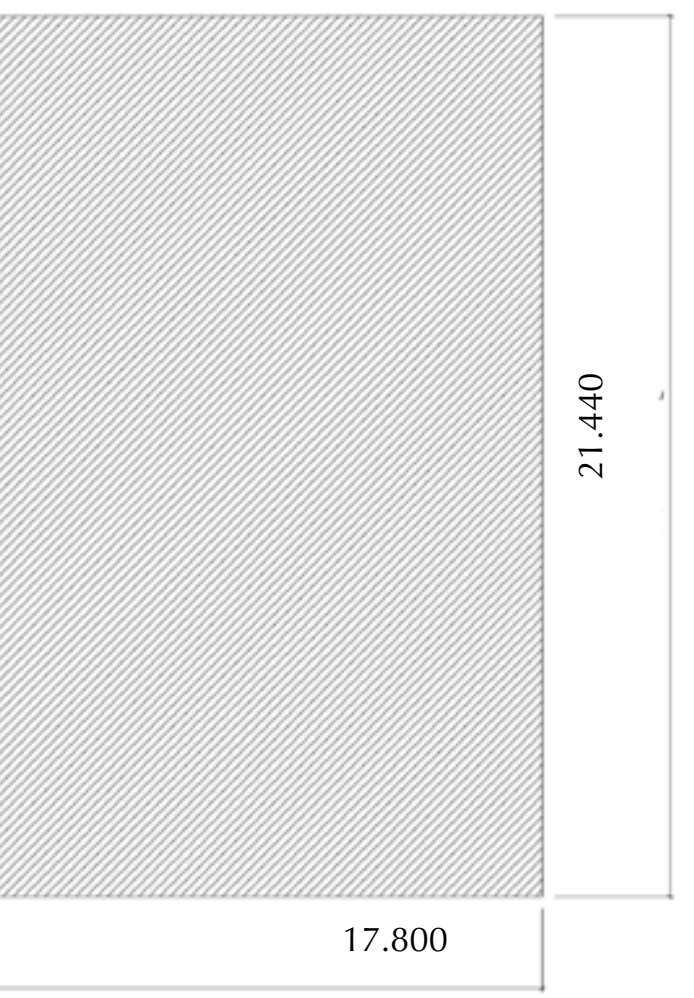

Tanque de agua: pudo ser instalado tiempo después, pero tiene la tarea de ser un suministro de agua para la población ante cualquier emergencia.

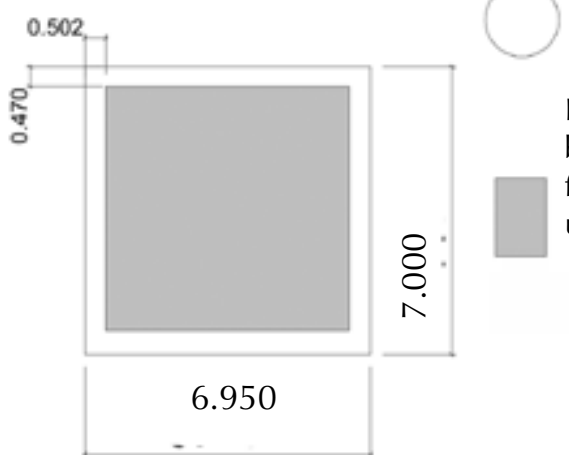

Bomba hidráulica: a simple vista la bomba de agua servía para llenar más fácilmente la pila o el que, al parecer, es un tanque de agua.
Pila de agua: la función de esta pila, dentro del pueblo, era brindar el agua a los pobladores para que cada uno fuera con sus recipientes y acarrearan el agua a sus hogares.

Materiales: se utilizó concreto armado que tiene una composición de grava, arena y cemento (varían porcentajes de cantidad en cada uno), y piedra volcánica.
Escala: 1:100

Unidad de medida: metros

FIGURAS 3a y 3b. Vivienda aún habitada. Prototipo de las viviendas construidas por la compañía minera (Plano: Cristian Mercado, 2016).

casas salían por las mañanas debido a la preparación del "lonche", que los niños vianderos pasaban por las casas recogiendo los alimentos para los trabajadores y cómo el silbato marcaba la hora para su comida. Éstos y otros movimientos son parte de la coreografía.

La presentación del baile de "El viandero" en Nueva Rosita despertó emociones en hombres y mujeres. Quienes se acercaron al profesor le expresaron: "me recordaste cuando mi papá llegaba con el recalentado"; otros de los comentarios fueron: "yo fui niño viandero, yo cobraba 5 centa- vos"; "yo todavía hago tortillas, todavía uso la lama para cocinar" (Anón. 2016c: comunicación personal).

Este primer caso es un ejemplo de cómo los sujetos seleccionan prácticas del pasado y hacen su propia interpretación apoyados en las artes. Es la memoria colectiva movilizada creativamente para transformarla en patrimonio intangible.

El segundo caso lo encontramos en la localidad de Rancherías, muni-

\footnotetext{
${ }^{7}$ Con el nombre de lama se conoce localmente al desecho del carbón mineral que sirve como combustible.
}

cipio de Múzquiz, donde la actividad minera se ha extinguido $y$, sin embargo, surgen grupos para reproducir la identidad con base en un repertorio de prácticas culturales en un día emblemático: el Día del Minero. ${ }^{8}$ En el siguiente párrafo detallamos cómo se dio esta iniciativa desde un grupo social, la cual identificamos en el tra-

\footnotetext{
${ }^{8} \mathrm{Si}$ bien el Día del Minero es el 11 de julio, se busca llevar a cabo esta ceremonia el sábado más próximo con la intención de que la gente que vive fuera de Rancherías (ya sea en la región o en los Estados Unidos) disponga de suficiente tiempo para los desplazamientos.
} 
bajo de campo. Nos guiamos con un par de preguntas: ¿por qué un grupo formado por mujeres (principalmente) reavivan el Día del Minero en un pueblo que ya no es su lugar de residencia y donde ya no hay minería?, ¿de qué artefactos echan mano para reavivar el sentido de comunidad en Rancherías? Detrás de estas preguntas está la reflexión sobre las formas que adquiere la cultura, según Giménez (2007:44), a saber: las formas interiorizadas referidas, por un lado, a los símbolos y estructuras mentales, $y$, por el otro, a las formas objetivadas, como los rituales y los objetos cotidianos, religiosos, artísticos, etcétera.

Para responder estas preguntas es necesario describir cómo empieza y funciona el Día del Minero, que es una iniciativa organizada por el grupo "Coterráneos de Rancherías". ${ }^{9}$ Esta organización nació cuando su principal promotora, una maestra jubilada, le sugirió a un profesor, también jubilado, que se reunieran algún día, pensando en una junta de pocas personas. Luego se le ocurrió abrir un grupo de Facebook, al que bautizó "Coterráneos de Rancherías", inspirado en una novela de Corín Tellado (Anón. 2016d: comunicación personal). De una plática de 5 personas, creció a una reunión de 400 , gracias a que encontraron un vehículo de comunicación en las redes sociales. Se conectaron migrantes residentes en Nava, Múzquiz, Parras de la Fuente, Saltillo (municipios de Coahuila); San Luis Potosí; Florida; Oklahoma; Texas; entre otros. Propusieron reunirse el 11 de julio, por ser el Día del Minero. Tuvimos la oportunidad de presenciar la segunda edición de esta celebración. La primera se recuperó mediante entrevista colectiva a las organizadoras.

\footnotetext{
${ }^{9}$ El grupo "Coterráneos de Rancherías" recibió apoyo financiero y en especie tanto de las autoridades municipales como de migrantes residentes en otras partes de la misma región o el estado y en los Estados Unidos. Sin embargo, la organización no ha derivado hacia fines políticos ni comerciales.
}

Para hacer posible esa conmemoración (más grande, como digo, de lo que se habían propuesto), las organizadoras - la mayoría, profesoras jubiladas de la región- gestionaron apoyo financiero principalmente de quienes están en los Estados Unidos y otras partes del norte de México, mientras que algunas personas residentes en Rancherías colaboraron en especie y con mano de obra. La festividad resultante, celebrada en la localidad de Rancherías, comprendió distintas actividades: una cabalgata (Figuras 4 y 5), una comida colectiva (Figura 6), una exposición de trajes típicos, juegos de beisbol, bailables folclóricos y una exposición de la historia del municipio de Nava (al norte de Coahuila, adonde ha emigrado gente de Rancherías). También se firmó una Carta de Hermandad con Nava, en agradecimiento por la recepción a los migrantes. Acudieron miembros residentes de la región, migrantes e integrantes de los pueblos indígenas kikapú y mascogo. En conjunto, la celebración se transformó en un amplio y diverso repertorio de artefactos culturales o formas objetivadas de la cultura de los que se echa mano para recordar y reforzar la autoidentificación o el reencuentro de la localidad consigo misma. De ninguna manera se está asumiendo que se trate de un grupo homogéneo donde todos participan y comparten el proyecto por igual. Las organizadoras hablan de "piedritas en el camino por celos", de que "la gente es difícil" (Anón. 2016d: comunicación personal) y de algunas personas que se comprometieron, pero, al final, no cumplieron. En esto coincidimos con algunos autores que comentan que los grupos "pasan por fases de extraordinaria cohesión y solidaridad colectiva, pero también por fases de declinación y decadencia que preanuncian su disolución" (Giménez 2007:67).

Ahora bien, surge la pregunta: ¿cómo se relacionan la identidad y el patrimonio cultural? Habíamos comentado que el grupo decidió realizar este encuentro en una fecha em- blemática por razón de que concentra el origen del lugar, el crecimiento tanto demográfico como físico de la población, la forma de sostenimiento de las familias y la formación de una cultura alrededor de la actividad minera, yagregamosque, si bien la minería en la localidad se ha visto reducida, muchos de los hombres de Rancherías continúan trabajando en minas de carbón de otras localidades. El Día del Minero es memoria colectiva actualizada.

El repertorio de artefactos culturales mencionado no obstante que es una construcción histórica (bailables, gastronomía, trajes típicos, etc.), finalmente también es una selección premeditada por parte de las organizadoras con el fin de reafirmar la identidad regional y local. En el caso analizado, además de los acervos culturales que podemos situar en el pasado, encontramos acciones proyectivas con las que se refuerzan los deseos de cambiar, impulsados por el pasado, el presente y el futuro. Para demostrar esto baste señalar que las organizadoras del Día del Minero en Rancherías tienen muy claro que se trata no sólo del festejo de un día, sino de una iniciativa que involucra mejoras en la localidad y oportunidades primordialmente para la juventud:

Tenemos que dejar huella en esto, y dijimos: pues vamos a ponernos a pintar las casas del pueblo. El año pasado, oye, pues a conseguir pintura. Aquí y allá, en la presidencia municipal y con amigos que económicamente estaban mejor, pues que yo les compro cinco latas. [...] Les decía yo: esto no se acaba con la fiesta, esto sigue [...] miren vamos a limpiar, miren no hay dinero para pagar pero vamos a limpiar y pues llevábamos lo de los refrescos y el agua y comenzamos a limpiar la entrada. [...] Después de que se acabó la fiesta el año pasado, empezamos con el sueño de la biblioteca: conseguir libros, y otra vez en las redes sociales (Anón. 2016d: comunicación personal). 

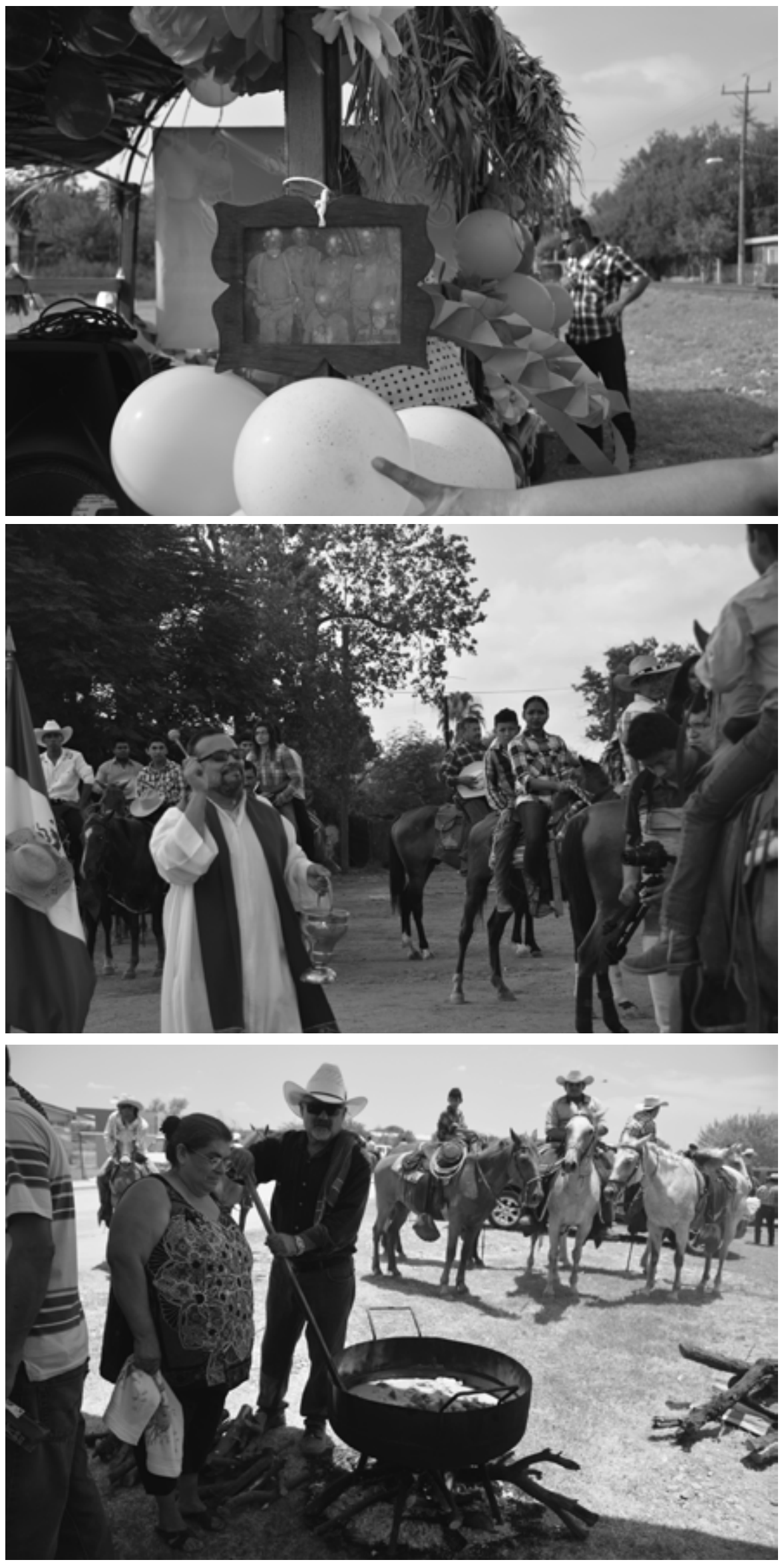

$\checkmark$ FIGURAS 4 y 5. Cabalgata hacia Rancherías (Fotografía: Camilo Contreras, 2016).

Con este caso mostramos que el patrimonio no es cosa del pasado, sino de éste y su relación con el presente y el futuro. Anteriormente citamos que el patrimonio es un proceso activo que ensambla series de objetos, prácticas y lugares que seleccionamos para contrastar con el presente, pero también con una serie de valores que deseamos conservar para el futuro.

"Dejar huella" no es únicamente una ambición individualista o del grupo organizador; la experiencia de las organizadoras (varias de ellas, cuando fueron maestras, tuvieron cargos directivos) convierte sus prácticas en un proyecto de corto y mediano plazos que se apoya en el pasado minero y en lo que mencionamos como cultura objetivada para transformar el presente y proyectar una idea de futuro: la movilización activa de la memoria como patrimonio.

\section{Reflexiones finales}

La gente es experta en la selección de su pasado, esto es, no solamente en su pasado, sino también en su selección desde sus condiciones del presente. Aunque este pasado sea una suma de artefactos y abstracciones - la casa, el festival, la plaza, la danza-, se objetiva en el presente. El patrimonio es un asunto social, es decir, pese a que lo que se patrimonializa sea privado en términos jurídicos, estos bienes son culturales en tanto forman parte de historias compartidas.

El patrimonio es creado por unos sujetos para quienes tiene sentido, pero a la vez impacta y extiende dicho sentido a otros sujetos, como los que crearon el baile de "El viandero" y los que lo vieron representado.

El segundo caso tratado nos muestra cuestiones ya conocidas, como que el patrimonio cultural es una

$\checkmark$ FIGURA 6. Preparación de alimentos para ofrecer a la comunidad (Fotografía: Camilo Contreras, 2016). 
construcción social desde el presente. Consiste en una construcción activa no sólo desde las instituciones sino también desde los colectivos sociales. Hay que decir, sin embargo, que en varias de las prácticas puestas en marcha por "Coterráneos de Rancherías" recibieron apoyo de autoridades municipales. Con todo y esto, es posible apreciar en este avance de la investigación que el repertorio de prácticas culturales puesta en escena del Día del Minero es una selección, o, mejor dicho, una interpretación del patrimonio desde el punto de vista de las organizadoras.

El análisis de la construcción del patrimonio debe acompañarse con el análisis de las intenciones, en este caso, explícitas con el pronunciamiento de las organizadoras de "dejar huella". El paisaje de Rancherías (limpia de calles, con la pintura aplicada a las casas) y los beneficiarios de la biblioteca y quienes disfrutan el convivio en el Día del Minero son algunas de esas "huellas" que están dejando "Coterráneos de Rancherías".

Finalmente, un punto para reflexionar es no crear una dicotomía entre los patrimonios material e inmaterial, en tanto se trata de un sistema cultural que, si bien tiene expresiones objetivas e interiorizadas, unas no se pueden entender a cabalidad sin las otras. Lo anterior equivale a evitar ver las prácticas, sitios, "lugares como puntos discretos y más bien entenderlos en su conexión con la vida de la gente" (Byrne 2008:157). Asumir que el Ilamado patrimonio material se entiende por sí mismo es cosificar la cultura y el patrimonio mismo.

\section{Agradecimientos}

Esta contribución está basada en avances del trabajo de campo para el proyecto "Patrimonio industrial minero. Exploración y posibilidades de valoración en la cuenca carbonífera de Coahuila", financiado por el Consejo Nacional de Ciencia y Tecnología (Conacyt), México, proyecto núm. 241524.

\section{Referencias}

Anón.

2016a Comunicación personal. Entrevista realizada por Camilo Contreras Delgado, 9 de julio.

2016b Comunicación personal. Entrevista realizada por Camilo Contreras Delgado, 9 de julio.

2016c Comunicación personal. Entrevista realizada por Camilo Contreras Delgado, 24 de junio.

2016d Comunicación personal. Entrevista realizada por Camilo Contreras Delgado, 9 de julio.

Bradley, Harried 1996 Fractured Identities: Changing Patterns of Inequality, Cambridge R. U.I Cambridge EE. UU., Polity Press.

Byrne, Denis 2008 "Heritage as social action", en Graham Fairclough, John Schofield, John H. Jameson y Rodney Harrison (eds.), The Heritage Reader, Londres, Routledge, 149-173.

Canales Santos, Álvaro

1989 El mineral de Palaú. Trozos de su historia, Saltillo, Universidad Autónoma de Coahuila.

Cerutti, Mario

1995 "Ferrocarriles y actividad productiva en el norte de México, 18801910. Inversión extranjera y división del trabajo al sur del río Bravo", en Carlos Marichal (coord.), Las inversiones extranjeras en América Latina, 1850-1930: nuevos debates y problemas en la historia económica comparada, México, Fondo de Cultura Económica/El Colegio de México/Fideicomiso Historia de las Américas (FCE/ Colmex/FHA), Serie Estudios, 178-192.

Contreras Delgado, Camilo 2002 "Reestructuración productiva y desplazamiento pendular de la fuerza de trabajo en la cuenca carbonífera de Coahuila, México", Investigaciones Geográficas. Boletín del Instituto de Geografía, 47:113-130.

Flores Morales, Ramiro 1993 San Felipe y El Hondo. Cuna de la región carbonífera de Coahuila, México, edición de autor.

Frosh, Stephen 1999 "Identity", en A. Bullock y S. Trombley (eds.), The New Fontana
Dictionary of Modern Thought, Londres, HarperCollins, 413.

Garden, Mary-Catherine E.

2009 "The heritagescape", en Marie Louise Stig Sorensen y John Carman (eds.), Heritage Studies. Methods and Approaches, Abingdon/Nueva York, Routledge, 270-291.

Giménez, Gilberto

2007 Estudios sobre la cultura y las identidades sociales, México, Consejo Nacional para la Cultura y las Artes/Instituto Tecnológico y de Estudios Superiores de Occidente (Conaculta/ ITESO).

Harrison, Rodney

2013 Heritage, Critical Approaches, Abingdon/Nueva York, Routledge/TayIor and Francis Group.

Minello, Nelson

1990 "El acero parece perder su temple", en México en el umbral del milenio, México, El Colegio de México (Colmex), 189-221.

Novelo, Victoria

1980 "De huelgas, movilizaciones y otras acciones de los mineros del carbón de Coahuila", Revista Mexicana de Sociología, 4 (42):1355-1377.

Reygadas, Luis

1988 Proceso de trabajo y acción obrera. Historia sindical de los mineros de Nueva Rosita, 1929-1979, México, Escuela Nacional de Antropología e Historia-Instituto Nacional de Antropología e Historia (ENAH-INAH)/ Ediciones Cuicuilco, Colección Divulgación, Serie Ensayos.

Sariego, Juan Luis

1988a Enclaves y minerales en el norte de México. Historia social de los mineros de Cananea y Nueva Rosita, 1900-1970, México, Centro de Investigaciones y Estudios Superiores en Antropología Social (CIESAS)/Ediciones Casa Chata.

1988b El Estado y la minería mexicana: política, trabajo y sociedad durante el siglo XX, México, Secretaría de Energía, Minas e Industria Paraestatal/ Instituto Nacional de Antropología e Historia (INAH)/Comisión de Fomento Minero.

Schwartz, Howard y Jerry Jacobs 1984 Sociología cualitativa, México, Trillas. 
Secretaría de Economía

2011 Panorama minero del estado de Coahuila, México, Servicio Geológico Mexicano/Secretaría de Economía.

Sommer, Ulrike

2009 "Methods used to investigate the use of the past in the formation of regional identities", en Marie Louise Stig Sorensen y John Carman (eds.), Heritage Studies. Methods and Approaches, Abingdon/Nueva York, Routledge, 103-120.

Sorensen, Marie Louise Stig

2009 "Between the lines and in the margins. Interviewing people about attitudes to heritage and identity", en Marie Louise Stig Sorensen y John Carman (eds.), Heritage Studies. Methods and Approaches, Abingdon/Nueva York, Routledge, 164-177.

Soriano, Fernanda y Erika P. Terrazas Ríos

2016 "Del coleccionismo al mecenazgo: el patrimonio cultural en Monterrey y Zacatecas", en Abel Rodríguez López (coord.), Sociedades mineras en América Latina, México, Secretaría de Cultura/Instituto Nacional de Antropología e Historia-Escuela de Antropología e Historia del Norte de México (INAH-EAHNM), 42-60.

Timón Tiemblo, María Pía

2012 “Definición, características y ámbitos de manifestación del patrimonio cultural inmaterial", en Miguel Ángel Álvarez Areces (ed.), Patrimonio inmaterial e intangible de la industria. Artefactos, objetos, saberes y memoria de la industria, Gijón, Industria, Cultura, Naturaleza/Centro de Iniciativas Culturales y Sociales (INCUNA/Cicees), Colección Ojos de la Memoria, 12.

\section{Síntesis curricular del/los autor/es}

\section{Camilo Contreras Delgado}

Departamento de Estudios Culturales (DEC),

El Colegio de la Frontera Norte (Colef), México camilo@colef.mx

Doctor en ciencias sociales (El Colegio de la Frontera Norte [Colef], México). Miembro del Sistema Nacional de Investigadores (SNI) del Conacyt (Consejo Nacional de Ciencia y Tecnología, México). Sus más recientes publicaciones son la coordinación de Ladrillos, fierros y memoria. Teoría del patrimonio industrial (2015, México, Colef), la autoría de Monterrey a través de sus calles. Una revisión desde las ciencias sociales (2015, México, Colef/Conarte/Conaculta) y el artículo "La industria textil en Monterrey, México. La formación de paisajes patrimoniales del presente" (Ábaco. Revista de Cultura y Ciencias Sociales, 88:162-168). Es investigador del Departamento de Estudios Culturales (DEC) de El Colegio de la Frontera Norte (Colef), México.

Postulado/Submitted: 21.09.2016

Aceptado/Accepted: 04.05.2017

Publicado/Published: 15.07.2017 